\title{
Quando a continuação é o caminho
}

Este é o primeiro número da nossa Revista no qual trabalho como EditorChefe, cargo para o qual fui honrosamente escolhido para cumprir ao longo dos próximos dois anos. Considerando os grandes avanços na qualidade, alcance e credibilidade da Revista construídos nos últimos anos pelo Editor-Chefe anterior, Dr. José Kawazoe Lazzoli, não há quem discorde de que o melhor caminho é continuar. Portanto, este é o nosso desafio e estímulo: continuar na mesma derivada positiva de crescimento e qualificação da $R e$ vista, o que poderá nos conduzir a duas metas físicas bem definidas: a indexação na SciELO - Scientific Eletronic Library Online (biblioteca virtual da BIREME) e no Index Medicus e seu seguimento eletrônico Medline. A indexação na SciELO (www.scielo.br) não só representará mais uma aprovação formal da qualidade da $R B M E$ como periódico, mas também permitirá disponibilizar a $R B M E$ na íntegra sob a forma eletrônica, ampliando o universo de leitores. O Index Medicus/Medline da National Library of Medicine dos EUA baseado no sistema MEDLARS ${ }^{\circledast}$ constitui o banco de dados de citações bibliográficas mais utilizado em todo o mundo para busca de publicações científicas periódicas na área biomédica (www.ncbi.nlm.nih.gov/entrez/query.fcgi). Por esta razão, ser indexado no Index Medicus/ Medline é hoje um certificado de qualidade científica e editorial respeitado internacionalmente.

Talvez fosse precoce pleitear indexação na SciELO e no Index Medicus/ Medline se considerássemos apenas nosso estágio atual de evolução, mas contatos iniciais indicam que temos condições concretas de, seguindo um planejamento estratégico adequado, nos tornarmos candidatos com chances reais de indexação a curto/médio prazo. Um processo muito rigoroso de avaliação técnica nos espera, mas estamos confiantes de que a conjunção dos esforços de editores, membros do conselho editorial, revisores ad-hoc, autores e leitores (incluindo administradores, estudantes e profissionais da área da Medicina do Exercício e Ciências do Esporte) construirá uma RBME capaz de conquistar os objetivos intermediários de qualidade necessários à nossa indexação na SciELO e no Index Medicus/Medline. Contamos com todos nesta nova fase de desafios internacionais!

Antonio Claudio Lucas da Nóbrega Editor-Chefe 